\title{
Source-Sink Relations in North American Ginseng Seedlings as Influenced by Leaflet Removal
}

\author{
John T. A. Proctor \\ Department of Plant Agriculture, University of Guelph, Guelph, Ontario, N1G 2W1, Canada \\ (Received November 11, 2008; Accepted December 20, 2008)
}

\begin{abstract}
Seedlings of North American ginseng (Panax quinquefolius L.) were grown to full canopy establishment and then leaflet or leaf removal at different times applied to determine the effects on plant growth and performance. Leaf removal at 47, 57, 69 and 78 days after seeding resulted in 82.1, 59.8, 41.3 and 29.8\% reduction, respectively, in root dry matter (economic yield) ; this indicates that leaf removal during the early root growth period causes greatest reduction in root yield. Removal of 1, 2, and 3 leaflets at 42, 52, 62 and 70 days from seeding reduced root weight at harvest (80 days from seeding) linearly, particularly at earlier removal dates. The perennating bud formed on all roots and was not influenced by treatment. This would suggest that if leaf loss occurs after canopy establishment the plant will re-grow the next year after the obligatory dormancy period.
\end{abstract}

Key words : North American ginseng, seedling, Leaflet Removal

\section{INTRODUCTION}

The production and maintenance of a healthy canopy on the slow growing herbaceous perennial North American ginseng (Panax quinquefolius L.) is essential for optimal growth of the economically important root. Root yield comprises two major components : individual root weight and the number of roots per unit area. Ginseng is propagated by seed. In the seedling year seed reserves are used initially to produce an epicotyl (stem) topped with a trifoliate leaf and a perennating bud is initiated in June ${ }^{1)} .{ }^{1)}$ below same The canopy contributes assimilate which is partitioned to the root $(62 \%)$, and stem plus leaves $(38 \%){ }^{2)}$

The young ginseng seedlings are susceptible to freeze damage $^{3)}$ and to diseases. ${ }^{4)}$ These damages can cause reduction in the photosynthetic area of seedlings and may disrupt the initiation of the perennating bud so vital in the growth of this perennial crop. There is no information on the quantitative relationship of leaf damage to root growth and to perennating bud initiation. By carrying out simulation studies of leaf damage it was hoped that quantitative, and possibly predictive, relationships between damage and root growth would be found.

\footnotetext{
\# To whom correspondence should be addressed.

(Tel) 519-824-4120; (Fax) 519-767-0755

(E-mail) jtprocto@uoguelph.ca
}

Therefore, the objective of this work was to grow ginseng seedlings under controlled environmental conditions, subject them to different degrees and timing of defoliation, and then assess the effects on root growth and plant performance. The objectives of Expt.1 were to determine the magnitude of dry matter loss, or gain, from complete leaf removal at different times during the growth of the seedling, and to see if defoliation influenced formation of the perennating bud which is needed for growth in the second year. The objective of Expt. 2 was to determine the effect of one, two or three leaflet (complete leaf) removal at different times, on the growth of the seedling.

\section{MATERIALS AND METHODS}

These experiments were carried out at the University of Guelph, Guelph, Ontario, latitude $43^{\circ} 32^{\prime} \mathrm{N}$, longitude $80^{\circ}$ $15^{\prime} \mathrm{W}$. Mature stratified seeds were purchased from a grower in October. The seeds were mixed with moistened mortar sand ( 1 seed/3 sand,v/v) and put in plastic containers. These containers were held in a controlled environment room $\left(4 \pm 1^{\circ} \mathrm{C}, 50 \pm 5 \%\right.$ relative humidity) until experiments were started in January or February. At that time $21 \mathrm{~cm}$ diameter pots were filled with ProMix BX® (Les Tourbieres Premier LTEE, Riviere du Loup, Quebec) which is a general purpose growing medium of 75 to $85 \%$ Canadian sphagnum peat moss, perlite and vermiculite, 
plus dolomitic limestone, calcium nitrate, potash, superphosphate, frittered trace elements, and a wetting agent. The $\mathrm{pH}$ of the mixture was about 6.0.

For each experiment 10 seeds were planted equidistant within each pot. The pots were placed in a greenhouse (21 $\pm 2^{\circ} \mathrm{C}$ day, $16 \pm 2^{\circ} \mathrm{C}$ night $)$ and shaded with knitted black polypropylene shade cloth to allow $78 \%$ of the outside light to reach the pots. For each experiment, which was repeated at least twice, there was a minimum of 4 pots per treatment. The leaf removal treatments varied and are described for each experiment.

Experiment (Expt 1). In this experiment the seedlings were allowed to become established (stage 109, Fig. 1a), 1) and 47, 57, 69 and 78 days after seeding the single trifoliate leaf and the stem were removed from the seedling. On day 105 all seedlings were harvested and the number of roots that had formed a perennating bud, stem length, leaf area, and dry weight at $80^{\circ} \mathrm{C}$ of the leaves, stems, and roots were measured.

Experiment (Expt.2). As in Expt.1 the seedlings were allowed to become established and on days 42, 52, 62, 72, one, two, or all three leaflets were removed. On day 80 all seedlings were harvested and measurements made as in Expt.1.

All data were analyzed, using the Statistical Analysis System package (SAS Institute Inc., Cary. N.C.).

\section{RESULTS AND DISCUSSION}

Expt.1. By Day 47 after seeding the stem (petiole) was fully extended, the leaf (of 3 leaflets) was horizontal and the crop canopy was complete. Between Day 47 and Day 105 stem length and dry weight, leaf area and dry weight did not change (Table 1). During the same period fresh and dry root weight and the root to shoot ratio increased linearly (Table 1$)$. The values for root: shoot ratio (0.35 to 1.58, Table 1) are in agreement with those for ginseng seedlings grown in growth chambers (0.2 to 1.6) and in greenhouses (1.4 to 1.8$).{ }^{8}$ ) The linear increase from 0.35 on Day 47 to 1.58 on Day $105\left(\mathrm{R}^{2}=0.97\right)$ is a direct reflection of root dry weight increase as stem and leaf dry weights remained constant over this period (Table 1).

Leaf removal at 47, 57, 69 and 78 days after seeding resulted in 82.1, 59.8, 41.3 and $29.8 \%$ reduction respectively (Table 1), in root dry matter (economic yield); this indicates that leaf removal during the early root growth period causes greatest reduction in root yield. These severe growth reductions in the early-mid growing season stress the importance of maintaining a healthy canopy at this time. As this was a linear reduction over time it would allow the development of a predictive equation $\mathrm{Y}$ $($ Root wt. decrease $)=-1.67 \mathrm{X}$ (Days from seeding $)+158$, $\mathrm{R}^{2}=0.98$. The defoliation treatments in this experiment removed more leaf area than would be expected from most leaf damage except spring freezes which can remove the entire leaf area. The effects of a wider range of defoliation treatments are considered in Expt.2. The perennating bud formed on all roots. Although there are no time course studies of perennating bud initiation in North American ginseng, Ahn and Kim, ${ }^{5)}$ studying Asian ginseng, showed that initation takes place very early in the growing season. Their study would suggest that perennating bud initiation occurred before the leaf removal treatments were applied in this study. Since leaf removal, as carried out here, did not influence the perennating bud, the plant would grow again after the necessary dormancy period. ${ }^{6)}$ The practical implications for cultivators of this crop is that if late frosts, ${ }^{3)}$ insects or diseases, ${ }^{4)}$ accidential loss of shade and associated photoinhibition damage, ${ }^{7)}$ or inadvertent leaf damage with an agrochemical occur after

Table 1. Effect of complete leaf and stem removal at 47, 57, 69 and 78 days after seeding on subsequent plant growth. Seedlings were harvested 105 days after seeding.

\begin{tabular}{|c|c|c|c|c|c|c|c|}
\hline \multirow{2}{*}{$\begin{array}{c}\text { Seedling } \\
\text { measurement }\end{array}$} & \multicolumn{5}{|c|}{ Leaf removal time : days from seeding } & \multirow{2}{*}{ Mean $^{2}$} & \multirow{2}{*}{$\begin{array}{c}\text { Statistical } \\
\text { significance }\end{array}$} \\
\hline & 47 & 57 & 69 & 78 & 105 & & \\
\hline Stem length $(\mathrm{cm})$ & 5.9 & 6.1 & 5.7 & 5.9 & 6.4 & 6.0 & ns \\
\hline Stem dry wt (mg) & 8.4 & 9.2 & 9.1 & 9.3 & 10.0 & 9.2 & ns \\
\hline Leaf area $\left(\mathrm{cm}^{2}\right)$ & 10.3 & 11.0 & 10.3 & 10.3 & 9.8 & 10.3 & ns \\
\hline Leaf dry wt (mg) & 23.6 & 27.1 & 26.0 & 28.4 & 29.6 & 26.9 & ns \\
\hline Root dry wt (mg) & $11.2(82.1)^{\mathrm{y}}$ & $25.1(59.8)$ & $36.7(41.3)$ & $43.9(29.8)$ & $62.5(100)$ & 35.9 & $\begin{array}{c}\text { linear } \\
\mathrm{R}^{2}=0.97\end{array}$ \\
\hline Root:shoot ratio & 0.35 & 0.64 & 1.04 & 1.16 & 1.58 & 0.95 & $\begin{array}{c}\text { linear } \\
\mathrm{R}^{2}=0.94\end{array}$ \\
\hline
\end{tabular}

\footnotetext{
$\mathrm{Z}$ Means across columns: $\mathrm{ns}=$ non-significant, $\mathrm{P}=0.05$.
}

$\mathrm{Y}$ ( ) Percent reduction in root dry weight compared to that at 105 days. 
Table 2. Effect of complete, one and two leaflet removal at 42, 52, 62, and 72 days after seedling on subsequent plant growth. Seedlings were harvested 80 days after seedling.

\begin{tabular}{|c|c|c|c|c|}
\hline Days after seeding & Leaflet treatment & Leaf area $\left(\mathrm{cm}^{2}\right)$ & Root dry wt. (mg) & $\begin{array}{c}\text { Stem and leaflet dry wt. (mg) } \\
\end{array}$ \\
\hline \multirow[t]{4}{*}{42} & $0^{Z}$ & 21.6 & 161 & 91 \\
\hline & 1 & 13.5 & 103 & 59 \\
\hline & 2 & 7.7 & 62 & 39 \\
\hline & 3 & 0 & 9 & 0 \\
\hline \multirow[t]{4}{*}{52} & 0 & 17.6 & 131 & 71 \\
\hline & 1 & 12.7 & 90 & 55 \\
\hline & 2 & 7.0 & 71 & 38 \\
\hline & 3 & 0 & 25 & 0 \\
\hline \multirow[t]{4}{*}{62} & 0 & 22.8 & 155 & 91 \\
\hline & 1 & 12.1 & 66 & 49 \\
\hline & 2 & 8.4 & 87 & 42 \\
\hline & 3 & 0 & 39 & 0 \\
\hline \multirow[t]{4}{*}{70} & 0 & 19.3 & 139 & 81 \\
\hline & 1 & 14.6 & 130 & 64 \\
\hline & 2 & 6.9 & 88 & 38 \\
\hline & 3 & 0 & 56 & 0 \\
\hline \multirow[t]{4}{*}{80} & 0 & 18.6 & 128 & 75 \\
\hline & 1 & 13.8 & 115 & 64 \\
\hline & 2 & 6.4 & 84 & 34 \\
\hline & 3 & 0 & 77 & 0 \\
\hline
\end{tabular}

$\mathrm{Z}_{0}=$ no leaflets removal, $1=1,2=2$, and $3=3$ leaflets removed

full plant height and leaf area have been attained, there will be loss in root dry matter but the plant will re-grow the following spring.

Expt. 2. The overall leaf area per seedling was $20.0 \mathrm{~cm}^{2}$ (Table 2). Removal of one leaflet reduced the area per seedling to $13.3 \mathrm{~cm}^{2}$ ( $66.6 \%$ of total leaf area, or $33.4 \%$ leaf area removed), and for two leaflets removed reduced the area to $7.3 \mathrm{~cm}^{2}(36.5 \%)$ [Table 2](Table 2). The treatments are illustrated in Fig. 1 and show the reduction in root size with leaflet area removal.

Root dry weight was reduced linearly by increasing leaflet removal, particularly at the earlier removal times (Table 2). Stem and leaflet dry weights were similarly reduced. Regression analysis of root dry weight against leaf area in Table 2 gave a range of $\mathrm{R}^{2}$ from 0.80 to 0.99 for the five different leaflet removal days and a mean of 0.83 for all data. This emphasizes the importance of maintaining a large healthy leaf area to maximize root dry weight (economic yield).

The regression equation for root dry weight and leaf area for all data was $\mathrm{Y}($ root $\mathrm{wt})=5.0 \mathrm{X}($ leaf area $)+39.7$. If it is assumed that this relationship is correct and appropriate then a $10 \%$ loss in leaflet area would reduce root weight by $49.7 \mathrm{mg}$, and by $59.7 \mathrm{mg}$ for a $20 \%$ loss. These estimates were calculated to compare with a 10 to $30 \%$ leaf thinning which reduced biomass yield of willow, Salix viminalis, significantly. ${ }^{9)}$ From these experiments Kendall and Wiltshire ${ }^{9)}$ proposed a figure of $10 \%$ defoliation as a threshold for significant impact on the yield of coppiced willows.

Unfortunately I did not include a $10 \%$ leaf removal treatment in these experiments but the above calculations suggest that minimal leaflet damage in ginseng will have a significant effect on root yield.

All roots in all treatments formed a perennating bud. Therefore leaf removal after canopy establishment, as carried out in Expt. 1, did not influence initiation of perennating buds. Plant establishment will occur the next growing season but the initial root weight will depend on the extent of the leaf damage (Table 2).

The manual defoliation treatments employed here obviously reduced the photosynthetic capacity of the seedlings by rapidly reducing the leaf area. Damage by various diseases, e.g. Ontario Ministry of Agriculture and Food, ${ }^{4}$ would be more gradual and progressive.

The findings from the present work emphasise > emphasize] the importance of maintaining a healthy ginseng seedling canopy, particularly early in the growing season, to maximize root yield. Appropriate well managed shade structures and implementation of a pest man- 
agement program, e.g. Ontario Ministry of Agriculture and Food, ${ }^{4)}$ are needed to ensure a healthy crop canopy. In these experiments perennating bud development was not influenced by the defoliation treatments. This ensures that despite leaf damage after full canopy development the seedlings will re-grow in the following year.

\section{ACKNOWLEDGMENTS}

I am indebted to Dean Louttit and Heather Proctor for technical assistance.

\section{REFERENCES}

1. Proctor, J. T. A., Dorais, M., Bleiholder, H., Willis, A., Hack, H. and Meier, V. : Phenological growth stages of North American ginseng (Panax quinquefolius). Ann. Appl. Biol.. 143, 311-317 (2003)

2. Proctor, J. T. A., Louttit, D. and Jiao, J. : Seasonal growth and root respiration of North American ginseng. J. Ginseng
Res. 22, 161-167 (1998).

3. Schooley, J. and Proctor, J. T. A. : Freeze damage to North American ginseng. HortTechnology 13, 697-701 (2003).

4. Ontario Ministry of Agriculture and Food : Production recommendations for ginseng, Publication 610 (2005).

5. Ahn, S-D. and Kim, Y. T. : Study on the formation of dormancy bud and inflorescence in young ginseng plant. Korean J. of Ginseng Sci.11, 111-117 (1987).

6. Lee, J. C., Strik, B. C. and Proctor, J. T. A. : Dormancy and growth of American ginseng as influenced by temperature. $J$. Amer. Soc. Hort. Sci. 110, 319-321 (1985).

7. Parmenter, G. and Littlejohn, R. P. : The effect of irradiance during leaf development on photoinhibition in Panax ginseng C.A. Meyer. J. Ginseng Res. 22, 102 -113 (1998).

8. Lee, J. C., Proctor, J. T. A. and Tsujita, M. J. : Air and rootzone temperature effects on the growth and yield of American ginseng. J. Hort. Sci. 61, 129-134 (1986).

9. Kendall, D.A. and Wiltshire, C. W. : Life-cycles and ecology of willow beetles on Salix viminalis in England. European J. of Forest Pathol. 28, 281-288 (1998). 